ACS Omega Supporting Information

\title{
An antimiR-155 cyclic peptide-PNA conjugate: synthesis, cellular uptake, and biological activity
}

\author{
Terese Soudah $^{\mathrm{a}}$, Saleh Khawaled ${ }^{\mathrm{b}}$, Rami I. Aqeilan ${ }^{\mathrm{b}}$, Eylon Yavin*a
}

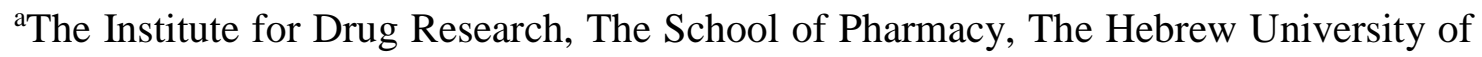
Jerusalem, Hadassah Ein-Kerem, Jerusalem 9112102, Israel.

${ }^{\mathrm{b}}$ Lautenberg Center for Immunology and Cancer Research, Institute for Medical Research Israel-Canada, The Hebrew University of Jerusalem, Hadassah Ein-Kerem, Jerusalem 9112102, Israel.

E-mail: eylony@ekmd.huji.ac.il; Fax:+972-2-6757574; Tel:+972-2-6758692. 


\section{Tables of contents:}

HPLC chromatograms of purified PNA-peptide conjugates

Figure $\mathrm{S} 1 \quad \mathrm{~S} 3$

Mass Spectra of purified $\mathrm{C}_{9}$-PNA and $\mathrm{C}_{9}$-PNA-Scr

Figure S2 S4

Mass Spectra of purified $\mathrm{dK}_{4}$-PNA and $\mathrm{dK}_{4}$-PNA-Scr

Figure S3 S5

HPLC chromatograms of crude FITC-labelled PNA-peptide conjugates

Figure S4 S6

HPLC chromatograms of purified FITC-labelled PNA-peptide conjugates

Figure S5 S7

Mass Spectra of purified FITC-labelled PNA-peptide conjugates

Figure S6 S8

Primer sequences

Table S1 S9

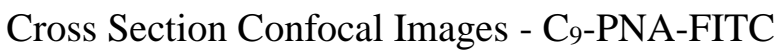

Figure S7 S10

Cross Section Confocal Images - C9-PNA-FITC co-stained

Figure S8 S10

XTT of Nf08-uterus normal cells

Figure S9 S11 

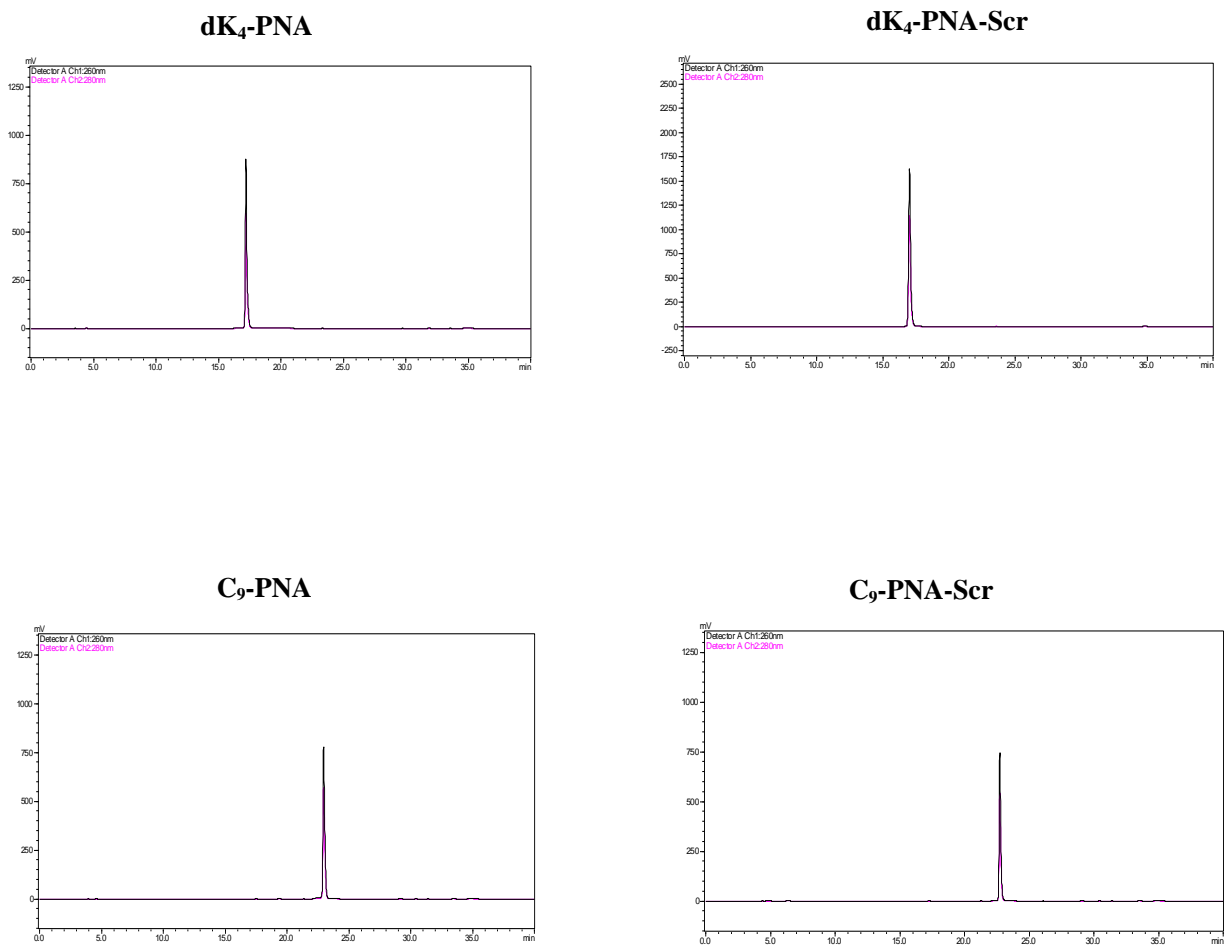

Figure S1. HPLC chromatograms of purified PNA-peptide conjugates. Over 95\% purity for all PNA-peptide conjugates.

RP-HPLC (Shimadzu LC2010), semi-preparative C18 reverse-phase column (Phenomenex, Jupiter $300 \mathrm{~A}$ ) at a flow rate of $4 \mathrm{~mL} / \mathrm{min}$. Mobile phase: $0.1 \%$ TFA in $\mathrm{H}_{2} \mathrm{O}(\mathrm{A})$ and acetonitrile (B).

Gradient: Initial $-90 \%$ A, $10 \%$ B. $10 \min -40 \%$ A, $60 \%$ B. $30 \min -10 \%$ A, $90 \%$ B. 30.01 $\min -10 \%$ A, $90 \%$ B. 37 min- $95 \%$ A, $5 \%$ B. 37.01 min- $95 \%$ A, 5\% B. 40 min-stop, 44.01 $\min$. 
D:IservicelYavinIEY-1492
positive

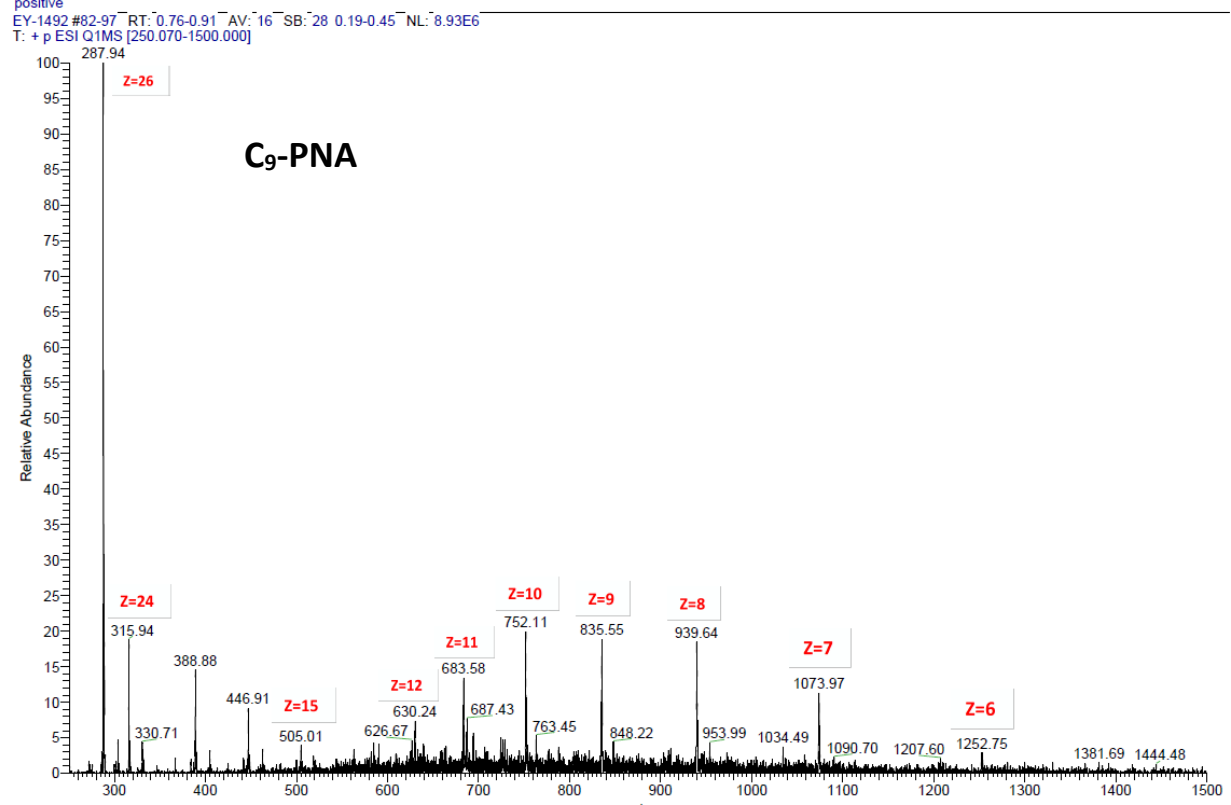

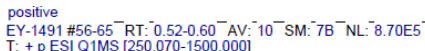

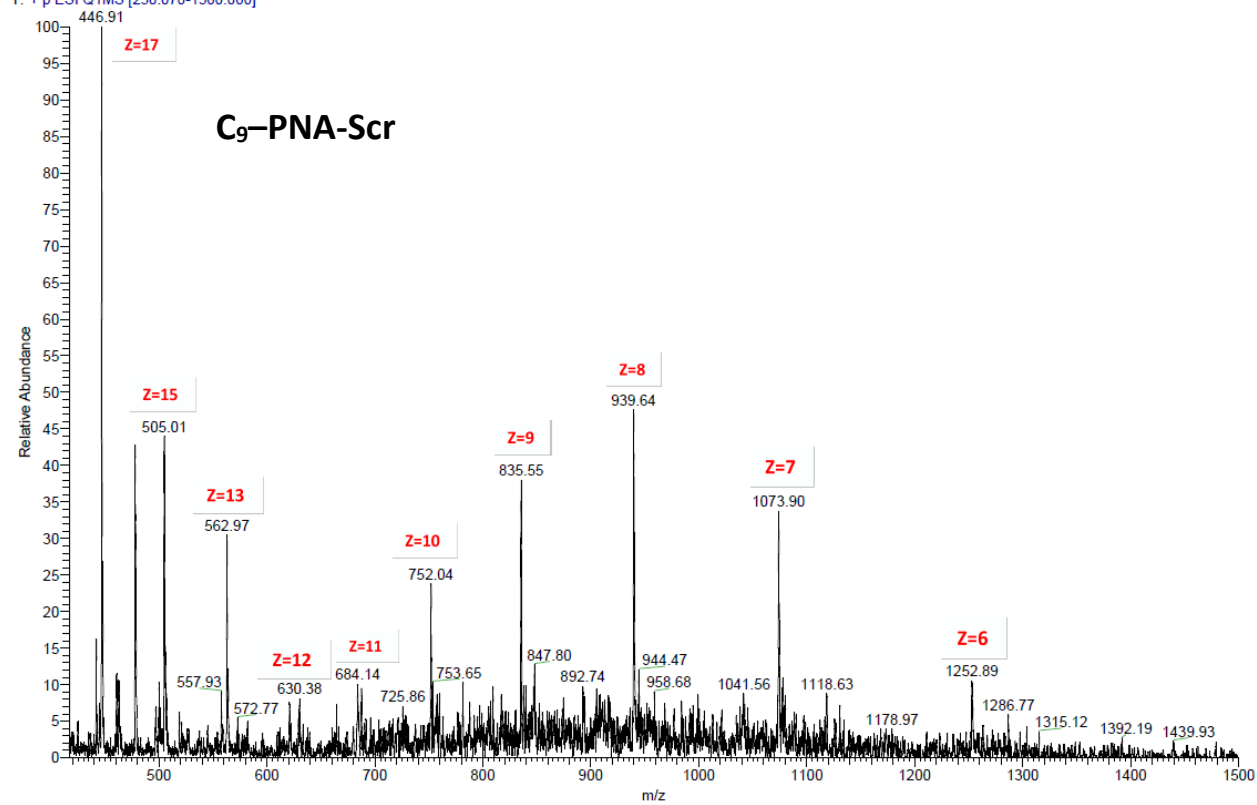

Figure S2. Mass spectra (ESI) of $\mathrm{C}_{9}$-PNA and $\mathrm{C}_{9}$-PNA-Scr. 

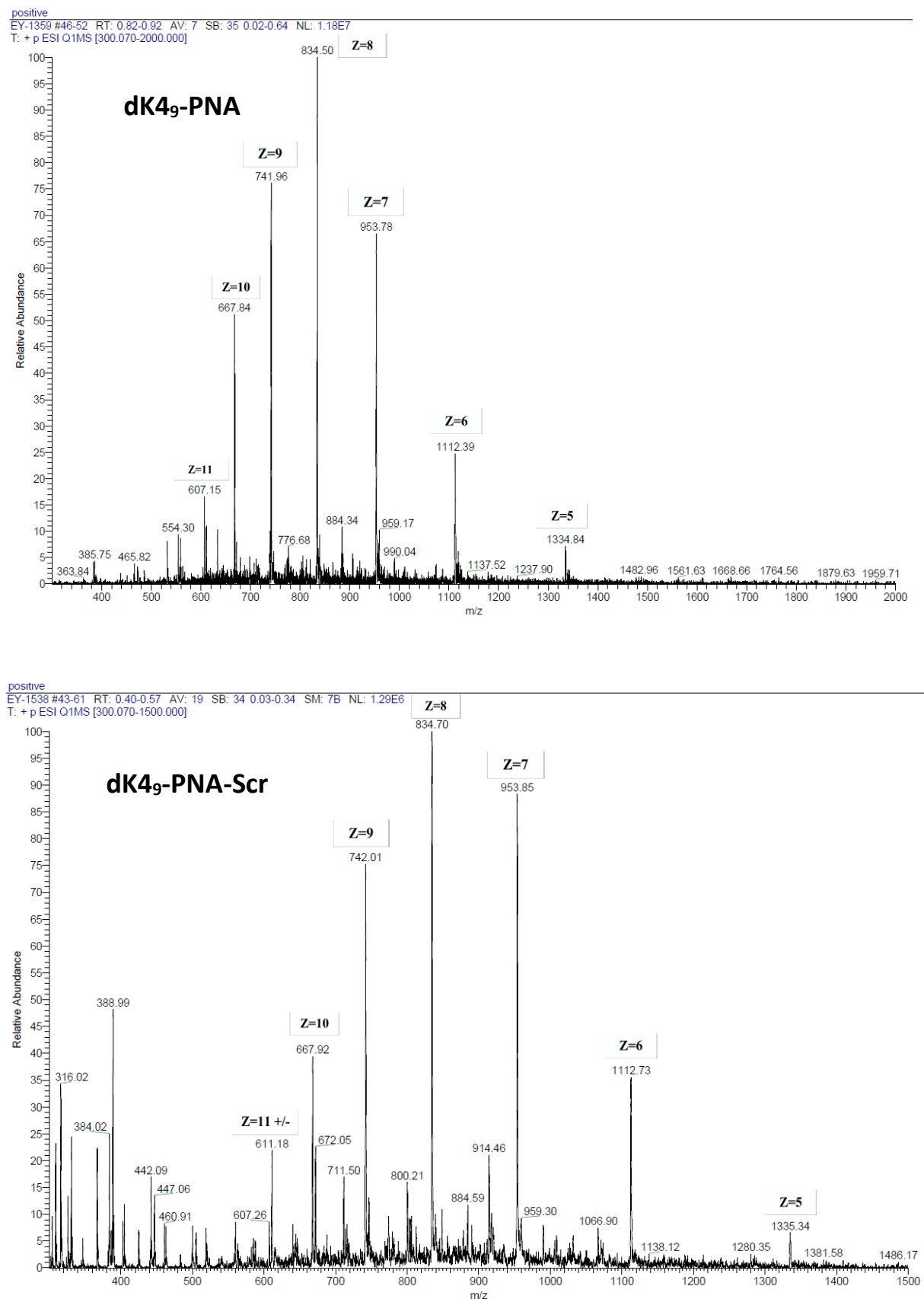

Figure S3. Mass spectra (ESI) of $\mathrm{dK}_{4}-\mathrm{PNA}$ and $\mathrm{dK}_{4}-\mathrm{PNA}-\mathrm{Scr}$. 

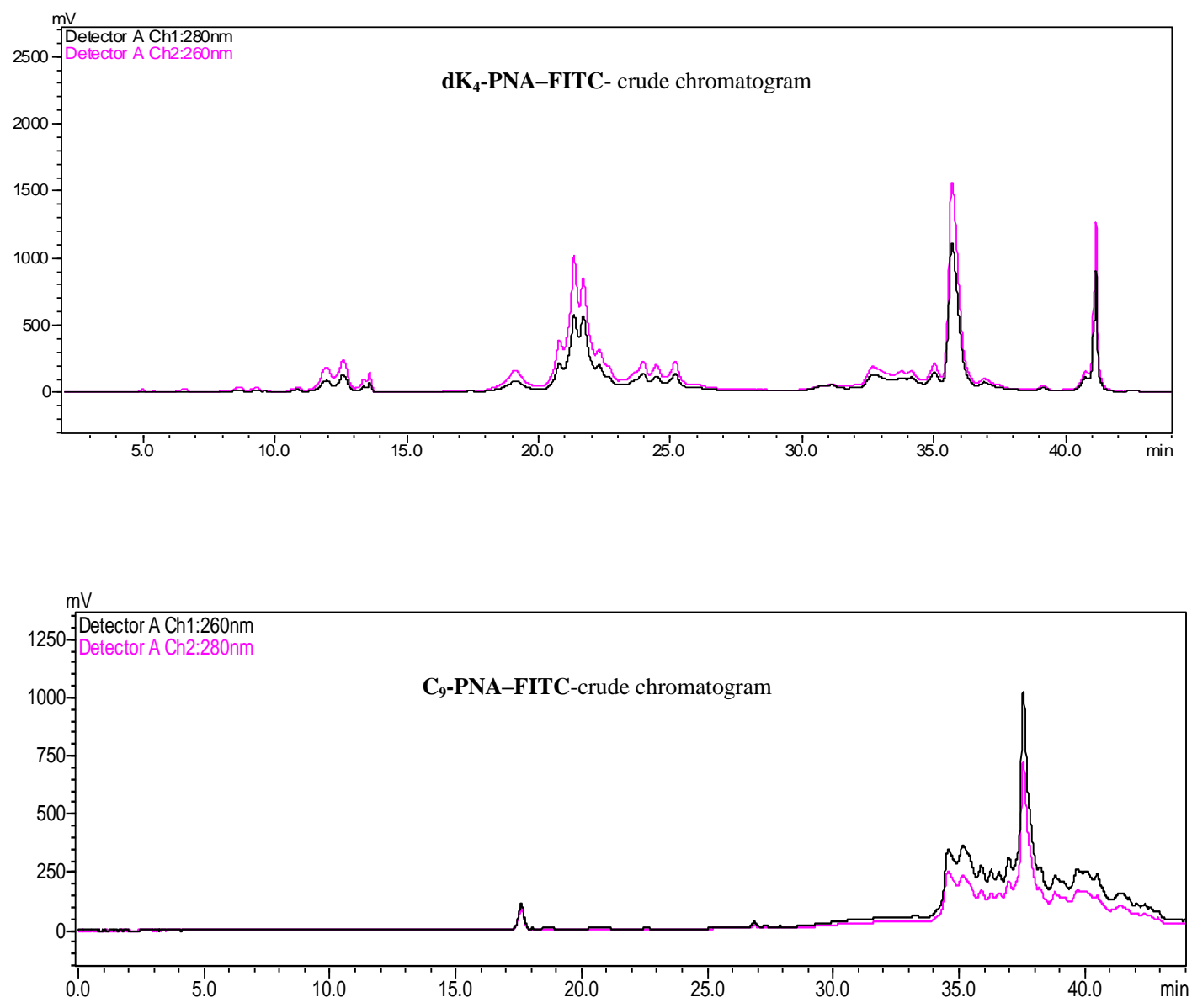

Figure S4. HPLC chromatograms of crude FITC-labeled PNA-peptide conjugates. Purity of FITC-labelled PNA-peptides were $22 \%$ for $\mathrm{dK}_{4}$-PNA-FITC $\left(\mathrm{R}_{\mathrm{t}}=35.9^{\prime}\right)$ and $36 \%$ for $\mathrm{C}_{9}$-PNAFITC $\left(\mathrm{R}_{\mathrm{t}}=36.8^{\prime}\right)$ based on the ratio between the area under curve (AUC) of product peak divided to total AUC (at $260 \mathrm{~nm}$ ).

RP-HPLC (Shimadzu LC2010), semi-preparative C18 reverse-phase column (Phenomenex, Jupiter $300 \mathrm{~A}$ ) at a flow rate of $4 \mathrm{~mL} / \mathrm{min}$. Mobile phase: $0.1 \%$ TFA in $\mathrm{H}_{2} \mathrm{O}(\mathrm{A})$ and acetonitrile (B).

Gradient: Initial $-90 \%$ A, $10 \%$ B. $10 \mathrm{~min}-80 \%$ A, $20 \%$ B. $30 \mathrm{~min}-10 \%$ A, $90 \%$ B. $30.01 \mathrm{~min}$ $-10 \%$ A, $90 \%$ B. $37 \mathrm{~min}-95 \%$ A, $5 \%$ B. $37.01 \mathrm{~min}-95 \%$ A, 5\% B. 40 min-stop, $44.01 \mathrm{~min}$. 
dK $\mathbf{4}$-PNA-FITC

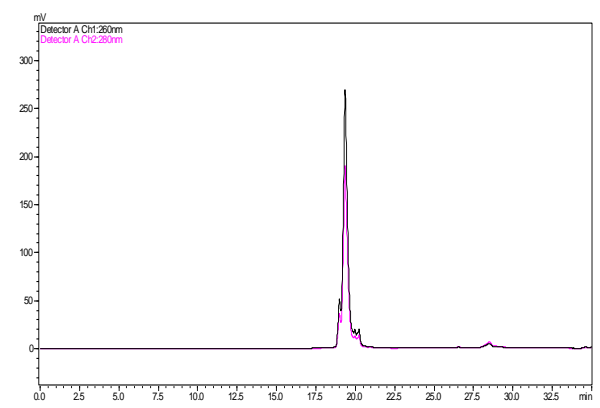

C9-PNA-FITC

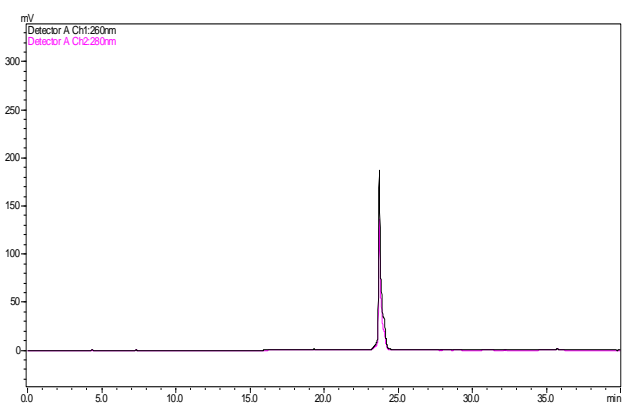

Figure S5. HPLC chromatograms of purified FITC-labeled PNA-peptide conjugates. Purity of FITC-labelled PNA-peptides: $91 \%$ for $\mathrm{dK}_{4}$-PNA-FITC and $93 \%$ for $\mathrm{C}_{9}$-PNA-FITC, respectively.

RP-HPLC (Shimadzu LC2010), semi-preparative C18 reverse-phase column (Phenomenex, Jupiter $300 \mathrm{~A}$ ) at a flow rate of $4 \mathrm{~mL} / \mathrm{min}$. Mobile phase: $0.1 \%$ TFA in $\mathrm{H}_{2} \mathrm{O}$ (A) and acetonitrile (B).

Gradient: Initial -90\% A, 10\% B. 10 min $-40 \%$ A, 60\% B. 30 min $-10 \%$ A, $90 \%$ B. 30.01 min $-10 \%$ A, $90 \%$ B. $37 \mathrm{~min}-95 \%$ A, $5 \%$ B. $37.01 \mathrm{~min}-95 \%$ A, $5 \%$ B. 40 min-stop, $44.01 \mathrm{~min}$. 

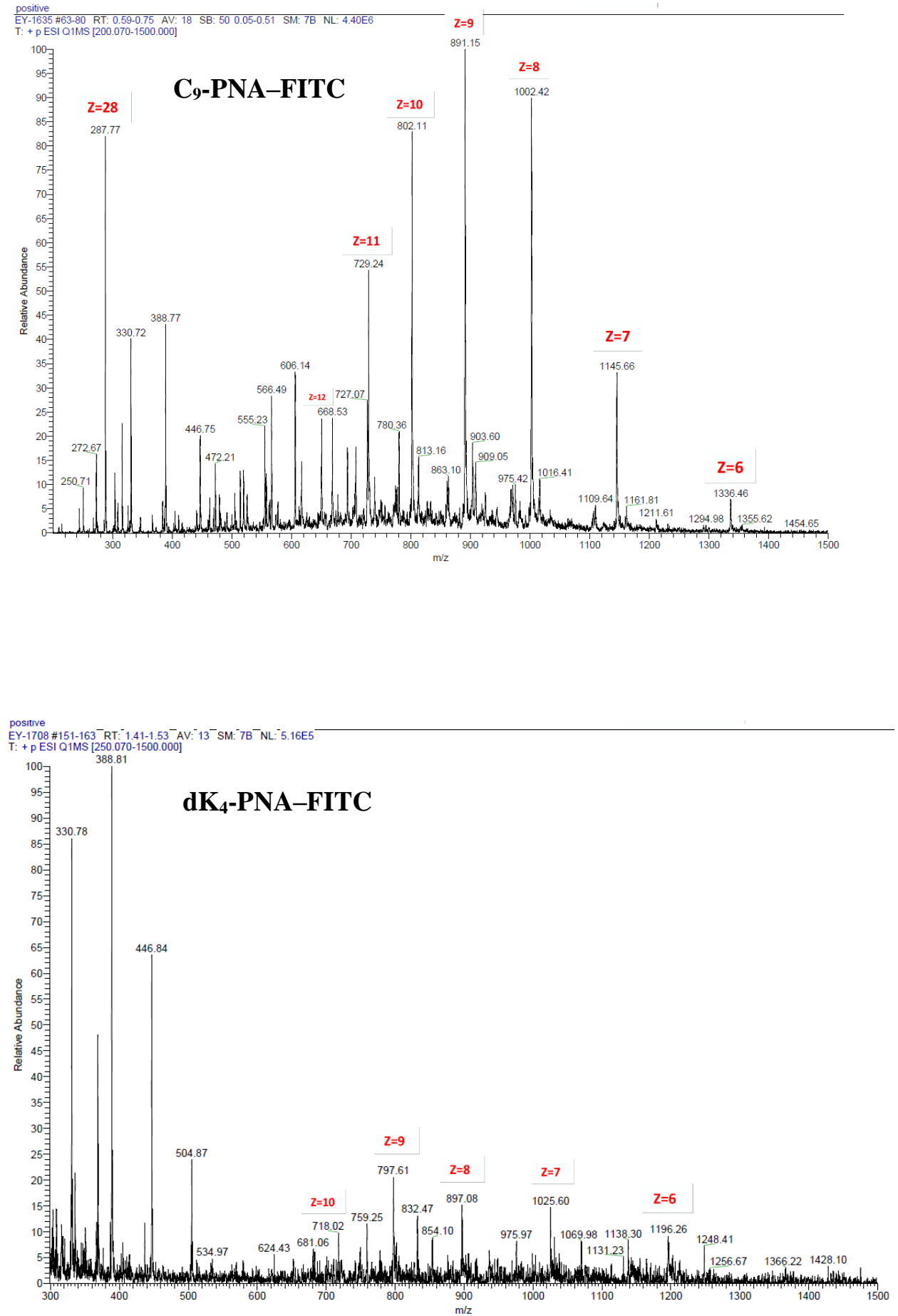

Figure S6. Mass spectra (ESI) of $\mathrm{C}_{9}$-PNA-FITC and dK4-PNA-FITC. 


\section{Primer sequences}

\begin{tabular}{|l|l|l|}
\hline Gene name & $\begin{array}{l}\text { Forward } \\
\text { reverse }\end{array}$ & Sequence $\left(\mathbf{5}^{\prime}-\mathbf{3}^{\prime}\right)$ \\
\hline$h U B C$ & For & ATTTGGGTCGCGGTTCTTG \\
\cline { 2 - 3 } & Rev & TGCCTTGACATTCTCGATGGT \\
\hline miR-155-5p & TTAATGCTAATCGTGATAGGGGT \\
\hline
\end{tabular}

Table S1: primers used for RT-PCR presented in Figure 1. 


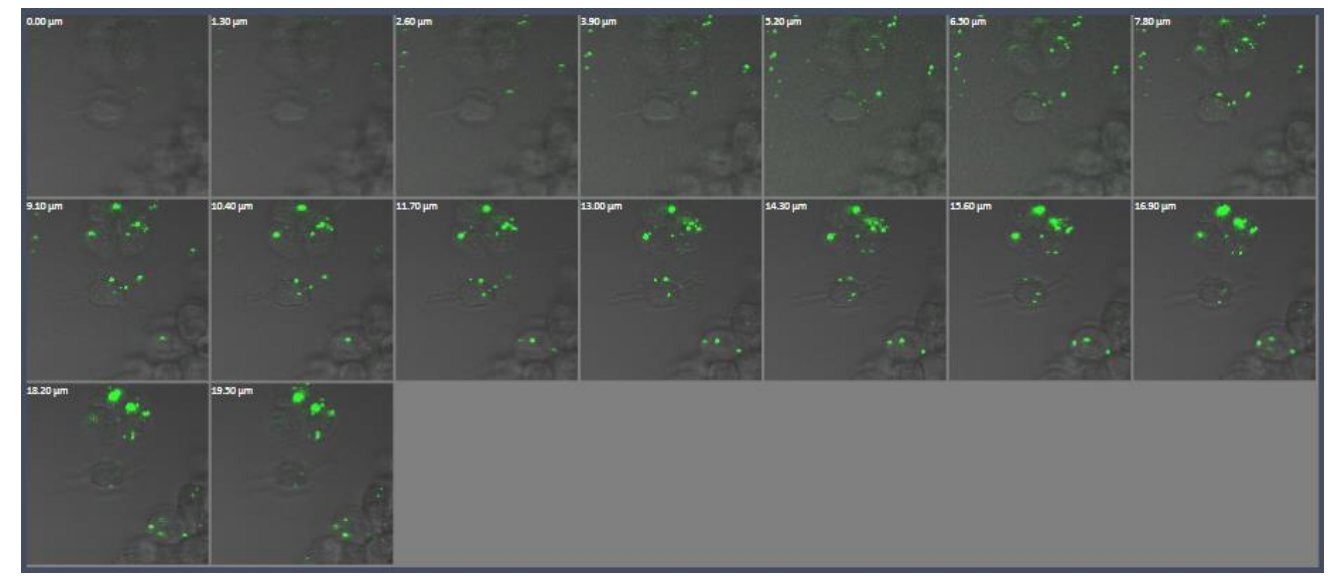

Figure S7. Cross section of a confocal image taken for C9-PNA-FITC added to U87 cells $(0.5 \mu \mathrm{M}, 3 \mathrm{~h})$. Sections are shown with increments of 1.3 microns ranging from 0 to 19.5 microns.

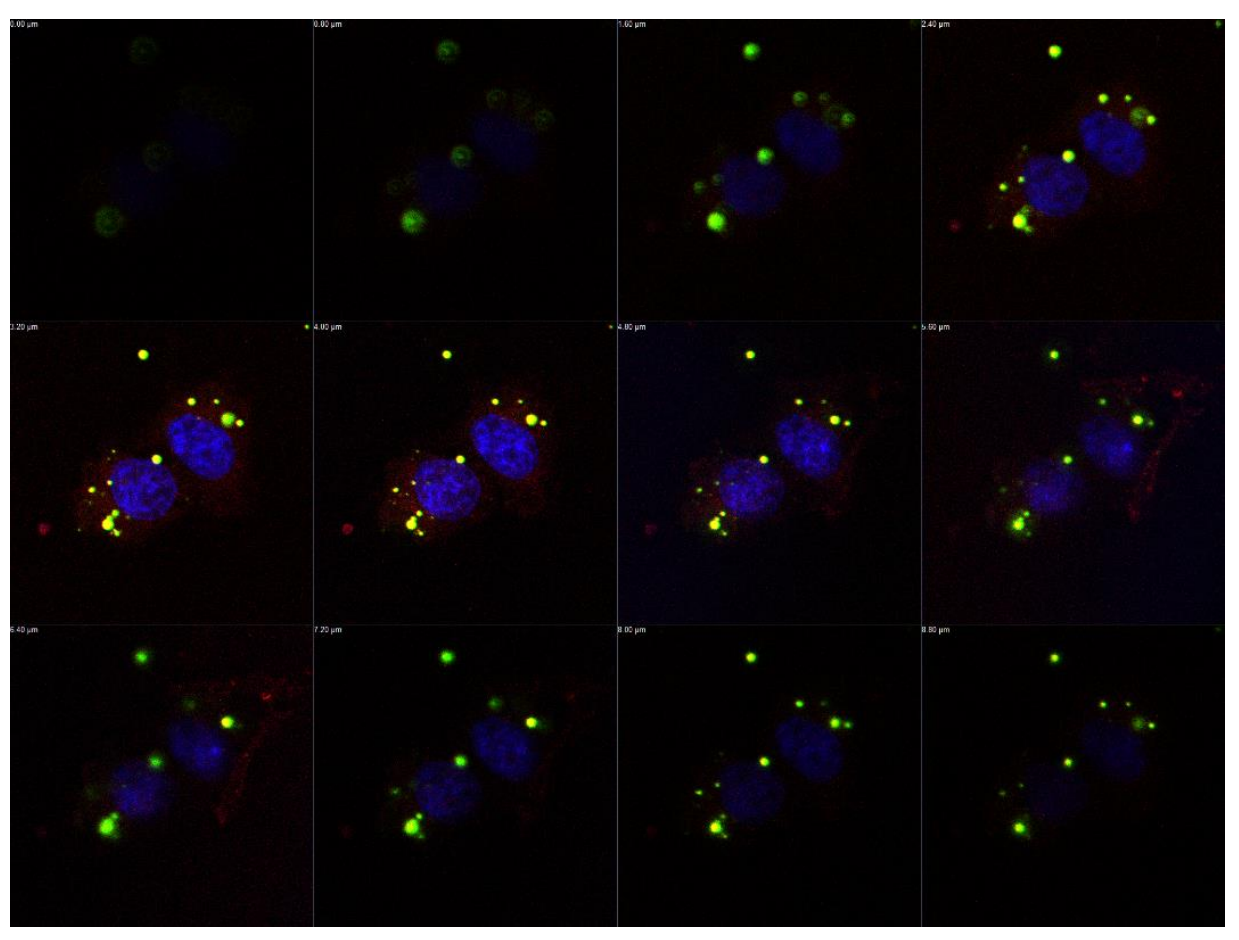

Figure S8. Cross section of a co-stained confocal image taken for $\mathrm{C}_{9}$-PNA-FITC added to U87MG cells $(0.5 \mu \mathrm{M}, 3 \mathrm{~h})$. Sections are shown with increments of 0.8 micron ranging from 0 to 8.8 microns. 


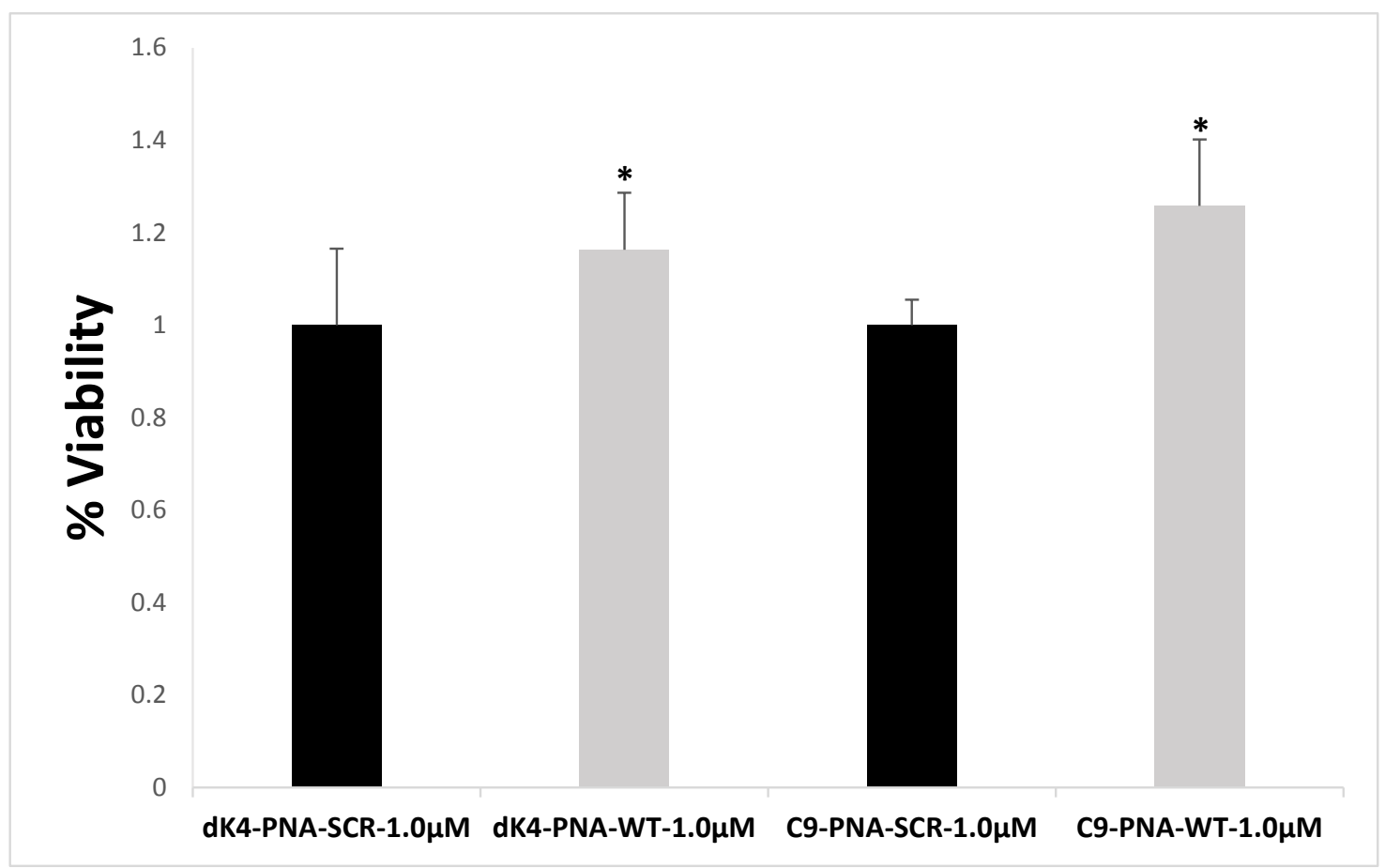

Figure S9. Cell viability for Nf08-uterus cells as determined by the XTT assay. Nf08uterus cells were treated with $1 \mu \mathrm{M}$ PNA conjugates for 72 hours at $37{ }^{0} \mathrm{C}$ (in triplicates in 96 -well plates). Viability is shown in comparison to scrambled PNA controls. ${ }^{*} P$ value $<0.05$. 